\title{
INTRODUÇÃO À PROBLEMÁTICA DA FUNDAMENTAÇC̃ÃO ÉTICO-POLÍTICA NA ERA DA CIÊNCIA SEGUNDO A FILOSOFIA PRAGMÁTICO-TRANSCENDENTAL DE KARL-OTTO APEL
}

Regenaldo Rodrigues da Costa*

SÍNTESE - A situação atual do ser humano é de uma crise global na qual as ameaças de guerra nuclear, de desastre ecológico e de colapso econômico apontam para o exterminio da biosfera humana. A racionalidade técnico-científica tornou possível esta situação de crise, entretanto, ela própria torna impossivel a fundamentação racional de uma ética que nos leve, em face do perigo comum, a assumir coletivamente a responsabilidade. Apel, porém, contesta a racionalidade técnico-científica e defende a fundamentação racional, intersubjetiva, de uma necessária orientação ético-política capaz de lidar com os grandes desafios que põem em risco a civilização humana no final do século XX.

PALAVRAS-CHAVE - Responsabilidade. Racionalidade técnico-científica. Fundamentação racional. Ética intersubjetiva. Orientação éticopolítica.
ABSTRACT - The present human condition is one of global crisis, one in which the threats of nuclear war, environmental disaster, and economic breakdown indicate the extermination of the human biosphere. The techno-scientific rationality has made such a crisis possible, but it has made impossible to provide the rational foundation of an ethic that would let us take collective responsibility in view of the danger we all face. Apel challenges the techno-scientific rationality and argues for the rational, intersubjective grounding of a much-needed ethico-political guidance which would let us deal with the serious challenges faced by mankind at the end of the twentieth century.

KEY WORDS - Responsibility. Techno-sicientific rationality. Rational grounding. Intersubjective ethic. Ethico-political guidance.

* Professor da Universidade Estadual do Ceará (UECE), doutorando em Filosofia na PUCRS e membro do Grupo Integrado de Pesquisa Dialética: conhecimento e linguagem, ética e filosofia política.

\begin{tabular}{|l|l|l|l|l|l|}
\hline VERITAS & Porto Alegre & v. 44 & n. 2 & Junho 1999 & p. $401-415$ \\
\hline
\end{tabular}




\section{O contexto planetário atual como ilustração para a necessidade de responder à pergunta pela condição de possibilidade de uma orientação ético-política na nossa era marcada pela ciência e pela técnica}

Para começar, tentaremos apresentar a visão de Apel acerca da situação do ser humano e, mais especificamente, a atual situação de crise da Humanidade. Mas, o que se entende aqui com atual "situação do ser humano"?

Para Apel, pode-se apresentar como características específicas da situação atual do ser humano o perigo da guerra nuclear de extermínio e também a crise ecológica, a qual ameaça destruir a biosfera humana, que atingem a Humanidade como um todo; assim, então, pela "[...] primeira vez na história mundial transcorrida até agora, se torna visível uma situação na qual os homens, em face do perigo comum, são desafiados a assumir coletivamente a responsabilidade [...]". 1

É nesta perspectiva, que, para Apel, além da responsabilidade de cada um em face do seu próximo e também além da responsabilidade política, no sentido convencional de "razão de estado", o homem atual se encontra diante da responsabilidade dos efeitos principais e colaterais de suas ações coletivas a nível planetário, e isto porque o potencial tecnológico da ciência teve como resultado um alcance planetário e trouxe como conseqüência um aumento do risco das atividades humanas, de modo que este também é planetário.

Ora, a bomba atômica colocou a guerra como um grave risco para toda a Humanidade e o mesmo vale, talvez em âmbito maior, para a exploração da Natureza pela técnica da moderna sociedade industrial, a qual trás conseqüências como a escassez de reservas energéticas, a destruição do meio ambiente, etc.

No entendimento de Apel, somente hoje se tomaram plenamente eficazes as não reprimidas incursões da técnica humana no espaço da Natureza e da vida e de tal modo que ameaçam destruir tudo que é vivo. Pois bem, durante muito tempo se esteve habituado com a concepção de que o controle técnico-científico do homem sobre a Natureza tinha sido atingido e que só era necessário complementá-lo pelo controle do homem sobre o homem. No entanto, aos poucos, começa a ficar claro que "[...] a relação do homem com a Natureza ainda inclui problemas bem diversos do que a mera exploração tecnológica de nosso conhecimento das leis causais (do anorgânico) para a realização de fins subjetivos da ação humana" (p. 167).

Pode-se dizer, portanto, que até agora muito nos omitimos, deixando de pôr nossa determinação subjetiva de fins em conexão com os quase finalísticos sistemas funcionais que subsistem na Natureza e co-condicionam a vida da espécie humana. Deste modo:

"A omissão de pôr as determinações humanas de fins em conexão com os sistemas funcionais naturais correspondeu à omissão de refletir também sobre os condicionantes funcionais biológico-ecológicos dos sistemas sociais humanos, mesmo em perspectivas econômicas e jụrídicas" (p. 167)

1 APEL, Karl-Otto. Estudos de moral moderna. Petrópolis: Vozes, 1994, p. 193. As referências a esta obra serão indicadas no texto apenas pelo número da página entre parênteses. 
E mais, para Apel, o triunfo do pensamento mecanicista na era contemporânea e a acusação de heretização de todo pensar teleológico-objetivo não deveriam ser inocentados desta questão.

Pois bem, poderíamos pensar que a nova situação problema da relação do homem com a Natureza e suas conseqüências, tais çomo a poluição ambiental, a superpopulação e sua ameaça ao esgotamento da biosfera, a ameaça da guerra nuclear, etc., deveriam ser capazes de minimizar a importância vital dos conflitos entre os homens, pois a consciência de que todos estão no mesmo barco e que têm um mesmo destino ecológico poderia levar os habitantes do planeta a subordinar todos os interesses divergentes ao interesse comum pela sobrevivência. No entanto, para Apel, as análises da situação existente induzem, antes, a esperar o contrário. Ora, isto se evidencia através do exemplo do enfrentamento da ameaça ecológica, pois:

"Na esfera política do cotidiano se comprovou, em todo o caso, que a ameaça ecológica, conjurada pelos experts, [...] não pôde ter sido evidenciada tão concretamente a ponto de influenciar sensivelmente 0 conflito dos [...] grupos de pressão, que limita 0 campo de ação dos políticos" (p. 168-169).

Poderia ser objetado, quanto à afirmação acima, que a influência da crise ecológica sobre o desenvolvimento dos conflitos sociais não deve se fazer notar na esfera de consciência da política do cotidiano e que ela num futuro próximo poderá tornar-se eficaz de modo automático pelo fato de a política de crescimento econômico não mais poder ser produzida em velho estilo.

Entretanto, para Apel, esta expectativa de assimilação automática da crise ecológica pela política de crescimento econômico, segundo todas as aparências, não levará a uma diminuição dos conflitos existentes entre os homens, mas antes ao ressurgimento de velhos conflitos e ao ressurgimento de conflitos clássicos.

Para ele, existem duas espécies fundamentais de conflitos sociais, que não são redutíveis uma à outra. A primeira, é "o conflito social de classes, que atualmente emerge nos aspectos regionalmente divergentes do conflito entre pobres e ricos (inclusive do conflito norte-sul) [...]" (p. 169). e a segunda, o conflito de prestígio e poder entre iguais, sobretudo entre nações. Ora, para Apel

“[..] nos últimos cem anos, o recrudescimento revolucionário da luta de classes [...] nos países industrializados ocidentais foi evitada principalmente em favor de compromissos de classes institucionalizados, pelo fato de, sempre de novo, poder ter sido posto em evidência um permanente crescimento econômico" (p. 170).

E mais:

"[...] o conflito entre pobres e ricos, que emergiu nos últimos decênios entre as nações industrializadas do Norte e as novas nações do Terceiro Mundo, sob a pressuposição de um constante crescimento econômico, pôde ser canalizado, até agora, no sentido da assim chamada politica desenvolvimentista" (p. 170).

Tomando estas considerações como pressuposto, Apel formula uma reflexão que conecta estes dois conflitos sociais e a crise ecológica, e de tal modo que ela implica uma mudança de perspectiva que torna obsoletas as saidas elaboradas, até agora, para os conflitos acima citados; ou seja, se por razões ecológicas, o 
crescimento econômico não puder ser promovido ou até tiver que ser desativado em favor de um almejável equilíbrio sistêmico, então, decairá, com isso, a motivação para a disponibilidade comprometida dos pobres ou dos apenas desprivilegiados.

Assim sendo, para Apel, devemos contar, provavelmente, com duas versōes alternativas de um renovado agravamento de um conflito de classes. A primeira versão ocorreria

“[...] quando as nações ricas, às custas das nações em desenvolvimento, tentassem a qualquer custo aumentar ainda mais seu standard de vida, ou pelo menos mantê-lo estável: neste caso [...] seria de esperar um agravamento catastrófico do conflito nortesul, enquanto a luta de classes no âmbito das nações industrializadas talvez pudesse ainda ser amainada" (p. 170).

Já a segunda versão, ocorreria

"quando - o que certamente não é provável - as ricas nações industrializadas fossem
realmente promover uma limitação do próprio crescimento econômico e, onde é possi-
vel, até do nível de vida de seus habitantes, em favor da distribuição geral da riqueza
exigida pelas nações em desenvolvimento" (p. 170 e 171).

Ora, para Apel, no caso da segunda versão ocorreria de imediato um renovado agravamento do clássico conflito de classes no âmbito das nações industrializadas, a não ser que as causas de tal conflito pudessem ser removidas por reformas modificadoras do sistema e uma política de distribuição de bens a nível mundial pudesse ser tomada compreensível e aceitável como resposta à questão da sobrevivência de todos. No entanto, conforme Apel

"[...] a circunstância de o conflito entre pobres e ricos, no sentido do conflito norte-sul, convergir em ampla escala para um conflito internacional, no sentido de uma luta por poder e prestígio na política externa, deixa claro, de imediato, que também este aspecto dos conflitos humanos não poderá ser minorado, sendo antes agravado por uma crise ecológica" (p. 171).

Entretanto, para ele, apesar da problemática do conflito norte-sul, a crise ecológica parece incentivar, de maneira branda, a realização de um entendimento a nível internacional, como, por exemplo, a crescente limitação da ampliação do mar territorial, os esforços para a salvação das baleias, a criação de reservas ecológicas, etc.

Isto, porém, não significa dizer que não haja um provável agravamento dos clássicos conflitos relacionados com a crise ecológica, os quais poderiam servir ao menos como ilustração para a necessidade de uma orientação ético-política fundamental em nossa era, marcada pela ciência e a tecnologia; no entanto, será possivel uma tal orientação racional ético-política em nossa era? Ou seja, é possível levantar racionalmente a questão ético-política: o que devemos fazer?

Para Apel, se faz necessário responder à pergunta pela possibilidade de tal orientação básica no contexto de uma ética filosófica, entretanto "[...] não é nada evidente que uma tal orientação normativa de base seja realmente possivel em sentido filosófico" (p. 164), e de tal modo que hoje se discute se é realmente possível fundamentar racionalmente algo como uma ética da responsabilidade solidária. 
E mais, para Apel, o triunfo do pensamento mecanicista na era contemporânea e a acusação de heretização de todo pensar teleológico-objetivo não deveriam ser inocentados desta questão.

Pois bem, poderíamos pensar que a nova situação problema da relação do homem com a Natureza e suas conseqüências, tais como a poluição ambiental, a superpopulação e sua ameaça ao esgotamento da biosfera, a ameaça da guerra nuclear, etc., deveriam ser capazes de minimizar a importância vital dos conflitos entre os homens, pois a consciência de que todos estão no mesmo barco e que têm um mesmo destino ecológico poderia levar os habitantes do planeta a subordinar todos os interesses divergentes ao interesse comum pela sobrevivência. No entanto, para Apel, as análises da situação existente induzem, antes, a esperar o contrário. Ora, isto se evidencia através do exemplo do enfrentamento da ameaça ecológica, pois:

"Na esfera politica do cotidiano se comprovou, em todo o caso, que a ameaça ecológica, conjurada pelos experts, [...] não pôde ter sido evidenciada tão concretamente a ponto de influenciar sensivelmente o conflito dos [...] grupos de pressão, que limita o campo de ação dos políticos" (p. 168-169).

Poderia ser objetado, quanto à afirmação acima, que a influência da crise ecológica sobre o desenvolvimento dos conflitos sociais não deve se fazer notar na esfera de consciência da política do cotidiano e que ela num futuro próximo poderá tornar-se eficaz de modo automático pelo fato de a política de crescimento econômico não mais poder ser produzida em velho estilo.

Entretanto, para Apel, esta expectativa de assimilação automática da crise ecológica pela política de crescimento econômico, segundo todas as aparências, não levará a uma diminuição dos conflitos existentes entre os homens, mas antes ao ressurgimento de velhos conflitos e ao ressurgimento de conflitos clássicos.

Para ele, existem duas espécies fundamentais de conflitos sociais, que não são redutíveis uma à outra. A primeira, é "o conflito social de classes, que atualmente emerge nos aspectos regionalmente divergentes do conflito entre pobres e ricos (inclusive do conflito norte-sul) [...]"' (p. 169). e a segunda, o conflito de prestígio e poder entre iguais, sobretudo entre nações. Ora, para Apel

“[... nos últimos cem anos, o recrudescimento revolucionário da luta de classes [...] nos países industrializados ocidentais foi evitada principalmente em favor de compromissos de classes institucionalizados, pelo fato de, sempre de novo, poder ter sido posto em evidência um permanente crescimento econômico" (p. 170).

E mais:

"[...] o conflito entre pobres e ricos, que emergiu nos últimos decênios entre as nações industrializadas do Norte e as novas nações do Terceiro Mundo, sob a pressuposição de um constante crescimento econômico, pôde ser canalizado, até agora, no sentido da assim chamada politica desenvolvimentista" (p. 170).

Tomando estas considerações como pressuposto, Apel formula uma reflexão que conecta estes dois conflitos sociais e a crise ecológica, e de tal modo que ela implica uma mudança de perspectiva que torna obsoletas as saídas elaboradas, até agora, para os conflitos acima citados; ou seja, se por razões ecológicas, o 
E mais, para Apel, o triunfo do pensamento mecanicista na era contemporânea e a acusação de heretização de todo pensar teleológico-objetivo não deveriam ser inocentados desta questão.

Pois bem, poderíamos pensar que a nova situação problema da relação do homem com a Natureza e suas conseqüências, tais como a poluição ambiental, a superpopulação e sua ameaça ao esgotamento da biosfera, a ameaça da guerra nuclear, etc., deveriam ser capazes de minimizar a importância vital dos conflitos entre os homens, pois a consciência de que todos estão no mesmo barco e que têm um mesmo destino ecológico poderia levar os habitantes do planeta a subordinar todos os interesses divergentes ao interesse comum pela sobrevivência. No entanto, para Apel, as análises da situação existente induzem, antes, a esperar o contrário. Ora, isto se evidencia através do exemplo do enfrentamento da ameaça ecológica, pois:

"Na esfera política do cotidiano se comprovou, em todo o caso, que a ameaça ecológica, conjurada pelos experts, [...] não pôde ter sido evidenciada tão concretamente a ponto de influenciar sensivelmente o conflito dos [...] grupos de pressão, que limita o campo de ação dos politicos" (p. 168-169).

Poderia ser objetado, quanto à afirmação acima, que a influência da crise ecológica sobre o desenvolvimento dos conflitos sociais não deve se fazer notar na esfera de consciência da política do cotidiano e que ela num futuro próximo poderá tornar-se eficaz de modo automático pelo fato de a política de crescimento econômico não mais poder ser produzida em velho estilo.

Entretanto, para Apel, esta expectativa de assimilação automática da crise ecológica pela política de crescimento econômico, segundo todas as aparências, não levará a uma diminuição dos conflitos existentes entre os homens, mas antes ao ressurgimento de velhos conflitos e ao ressurgimento de conflitos clássicos.

Para ele, existem duas espécies fundamentais de conflitos sociais, que não são redutíveis uma à outra. A primeira, é "o conflito social de classes, que atualmente emerge nos aspectos regionalmente divergentes do conflito entre pobres e ricos (inclusive do conflito norte-sul) [...]" (p. 169). e a segunda, o conflito de prestígio e poder entre iguais, sobretudo entre nações. Ora, para Apel

“[...] nos últimos cem anos, o recrudescimento revolucionário da luta de classes [...] nos países industrializados ocidentais foi evitada principalmente em favor de compromissos de classes institucionalizados, pelo fato de, sempre de novo, poder ter sido posto em evidência um permanente crescimento econômico" (p. 170).

E mais:

“[...] o conflito entre pobres e ricos, que emergiu nos últimos decênios entre as nações industrializadas do Norte e as novas nações do Terceiro Mundo, sob a pressuposição de um constante crescimento econômico, pôde ser canalizado, até agora, no sentido da assim chamada politica desenvolvimentista" (p. 170).

Tomando estas considerações como pressuposto, Apel formula uma reflexão que conecta estes dois conflitos sociais e a crise ecológica, e de tal modo que ela implica uma mudança de perspectiva que torna obsoletas as saídas elaboradas, até agora, para os conflitos acima citados; ou seja, se por razões ecológicas, o 
crescimento econômico não puder ser promovido ou até tiver que ser desativado em favor de um almejável equilíbrio sistêmico, então, decairá, com isso, a motivação para a disponibilidade comprometida dos pobres ou dos apenas desprivilegiados.

Assim sendo, para Apel, devemos contar, provavelmente, com duas versões alternativas de um renovado agravamento de um conflito de classes. A primeira versão ocorreria

"[...] quando as nações ricas, às custas das nações em desenvolvimento, tentassem a qualquer custo aumentar ainda mais seu standard de vida, ou pelo menos mantê-lo estável: neste caso [...] seria de esperar um agravamento catastrófico do conflito nortesul, enquanto a luta de classes no âmbito das nações industrializadas talvez pudesse ainda ser amainada" (p. 170).

Já a segunda versão, ocorreria

“quando - o que certamente não é provável - as ricas nações industrializadas fossem realmente promover uma limitação do próprio crescimento econômico e, onde é possivel, até do nivel de vida de seus habitantes, em favor da distribuição geral da riqueza exigida pelas nações em desenvolvimento" (p. 170 e 171).

Ora, para Apel, no caso da segunda versão ocorreria de imediato um renovado agravamento do clássico conflito de classes no âmbito das nações industrializadas, a não ser que as causas de tal conflito pudessem ser removidas por reformas modificadoras do sistema e uma política de distribuição de bens a nível mundial pudesse ser tornada compreensivel e aceitável como resposta à questão da sobrevivência de todos. No entanto, conforme Apel

“[... ] a circunstância de o conflito entre pobres e ricos, no sentido do conflito norte-sul, convergir em ampla escala para um conflito internacional, no sentido de uma luta por poder e prestígio na politica externa, deixa claro, de imediato, que também este aspecto dos conflitos humanos não poderá ser minorado, sendo antes agravado por uma crise ecológica" (p. 171).

Entretanto, para ele, apesar da problemática do conflito norte-sul, a crise ecológica parece incentivar, de maneira branda, a realização de um entendimento a nivel internacional, como, por exemplo, a crescente limitação da ampliação do mar territorial, os esforços para a salvação das baleias, a criação de reservas ecológicas, etc.

Isto, porém, não significa dizer que não haja um provável agravamento dos clássicos conflitos relacionados com a crise ecológica, os quais poderiam servir ao menos como ilustração para a necessidade de uma orientação ético-política fundamental em nossa era, marcada pela ciência e a tecnologia; no entanto, será possivel uma tal orientação racional ético-política em nossa era? Ou seja, é possivel levantar racionalmente a questão ético-política: o que devemos fazer?

Para Apel, se faz necessário responder à pergunta pela possibilidade de tal orientação básica no contexto de uma ética filosófica, entretanto "[...] não é nada evidente que uma tal orientação normativa de base seja realmente possível em sentido filosófico" (p. 164), e de tal modo que hoje se discute se é realmente possível fundamentar racionalmente algo como uma ética da responsabilidade solidária. 


\section{A aparente impossibilidade de uma fundamentação racional da ética da responsabilidade intersubjetivamente válida}

Para Apel, o risco dos efeitos colaterais de nossas atividades técnicoindustriais em medida planetária e que ameaçam destruir a vida humana e planetária deveria hoje ser responsabilizado por nós, daí por que, para ele, "[...] não é uma ética de conviç̧ão, mas de responsabilidade a que é exigida” (p. 173).

Entretanto, segundo Apel, a ética da responsabilidade situacional não corresponde à exigência desta hora, pois "[...] o que na atual crise da civilização técnico-científica seria exigido em medida planetária é muito mais do que uma ética de situações limites existenciais" (p. 173). Ora, para ele, se exige algo como uma ética da responsabilidade solidária da Humanidade no sentido de uma intermediação comunicativa de interesses e ponderação da situação.

Importa, pois, perguntar sobre a possibilidade de uma fundamentação racional de validade intersubjetiva de tal ética. Pois bem, conforme Apel, a tentativa de responder a esta pergunta parece resultar em uma situação paradoxal na medida em que

“[...] a ciência que, por suas seqüelas tecnológicas se constitui numa causa fundamental para a necessidade prática de uma responsabilidade solidária [...], através do conceito de racionalidade por ela moldado, no sentido de uma objetividade neutra (de valor), parece ser causa ou fundamento para a impossibilidade de fundamentação racional de uma ética intersubjetivamente válida" (p. 173 e 174).

Segundo Apel, é assim que se apresenta a situação se tomarmos em consideração os recursos racionais da filosofia analítica do Ocidente. Pois bem, isto ocorre porque na filosofia analitica são pressupostas três premissas axiomáticas para qualquer fundamentação de normas éticas.

A primeira premissa afirma que "fundamentação racional tem o mesmo significado que dedução lógico-formal de sentenças a partir de sentenças, num sistema de sentenças sintático-semânticas axiomatizadas" (p. 174); já a segunda premissa afirma que "validade intersubjetiva de sentenças tem o mesmo significado que validade objetiva, no sentido de constatação neutra dos fatos ou de conclusão lógico-formal" (p. 174); e, finalmente, a terceira premissa, que "de constatações factuais não é possivel deduzir, através de conclusões lógicas, nenhum juizo de valor ou asserção normativa [...]" (p. 174).

Para Apel, se tomarmos estas premissas como pressupostos para o sentido de fundamentação racional, é logicamente impossivel uma fundamentação racional de normas éticas, pois, a rigor, bastaria só a primeira premissa para demonstrar a impossibilidade de uma fundamentação racional.

Ora, Hans Albert ressalta que cada tentativa de uma fundamentação lógicoformal de sentenças a partir de sentenças resulta em três conseqüências: em primeiro lugar, esta tentativa resulta em um regresso ao infinito, pois os axiomas que sustentam a dedução devem também, para serem válidos, ser deduzidos num sistema sentencial axiomático e assim ao infinito; em segundo lugar, ela resulta em um círculo lógico, pois sentenças carecedoras de fundamentação são, na dedução, postas como sentenças de base; e, finalmente, o processo de fundamentação para não se direcionar ao infinito, o que é irrealizável, deve ser interrompido por um destaque dogmático de determinadas premissas. 
Para Apel, “[...] esta demonstração da impossibilidade de uma fundamentação última [...] apresenta não só a impossibilidade da fundamentação da norma ética, mas também a impossibilidade de qualquer espécie de fundamentação última [...]" (p. 175) e, inclusive, dela própria enquanto demonstração da impossibilidade de uma fundamentação racional.

Ora, quando a fundamentação é equiparada à dedução lógico-formal de sentenças a partir de sentenças, então se condena, de saída, ao fracasso qualquer espécie de fundamentação ética e teorético-científica, de modo que a validade intersubjetiva de sentenças normativas não pode ser fundamentada; além do mais, as sentenças normativas não são consideradas intersubjetivamente válidas, pois não são deduzidas de fatos objetivamente válidos, ou seja, isentos de juízos de valor.

Assim sendo, não pode haver normas éticas intersubjetivamente válidas e nem fundamentadas racionalmente e mais, "[...] na filosofia analítica do Ocidente isto é geralmente explicado de forma que as normas ou valorações [...] deveriam ser reportadas a sentimentos meramente subjetivos ou a decisões aleatórias" ( $p$. 175), de modo que os juízos morais têm a ver com sentimentos subjetivos, logo, privados e com decisões aleatórias, logo, arbitrárias.

É nesta direção que, para Apel, transparece a conexão entre as conseqüências meta-éticas da filosofia analítica e do existencialismo, pois estas duas tendências representativas da filosofia ocidental concordam abertamente que a ética é um assunto de decisão subjetiva, privada e, em última instância, irracional.

Ora, para Apel, nestas duas tendências não existem antagonismos inconciliáveis, pois, embora elas tenham uma relação suplementar reciprocamente excludente, ao mesmo tempo, elas têm uma relação complementar, ou seja, "a filosofia analítica, como ciência da lógica, tem a ver com o campo [...] da racionalidade isenta de valor; o existencialismo [...] tem a ver com a esfera privada das decisões subjetivas da consciência" (p. 176).

Pois bem, esta complementaridade da filosofia analítica e do existencialismo implica que não é absolutamente possível nenhuma justificação racional de quaisquer normas com pretensão de validade intersubjetiva e nem tão pouco a justificação da validade intersubjetiva do princípio da liberdade da consciência subjetiva pessoal e nem mesmo da concordância entre representação de interesses, que forma a base da democracia liberal.

Assim sendo, a filosofia ocidental, com sua mais recente forma de crítica da fundamentação e com os pressupostos do conceito de racionalidade científica, implica como resultado a impossibilidade de fundamentar obrigatoriedades éticas, de modo que "[...] todo o ethos da democracia liberal se reduz, então, a dispositivos de prudência [...] pensáveis, em princípio, numa comunidade de gângsteres" (p. 177); e a obrigatoriedade ou validade normativa dos acordos e as leis normativas sobre eles fundadas podem ser reduzidas a uma efetividade factual em função dos interesses persistentes. 
Ora, "se realmente é impossivel uma fundamentação de validade intersubjetiva de normas éticas, então não subsiste nenhuma obrigação de aceitar ou cumprir acordos livres" (p. 177), ou seja, cada um é obrigado a aceitar ou respeitar acordos apenas enquanto espera vantagens dos mesmos ou enquanto por conduta adversa espera deles ter prejuizos; assim, por conseguinte, não há propriamente obrigatoriedade normativa, pois a obrigatoriedade normativa é reduzida a efetividade de estratégias em função da finalidade, muitas vezes irracionais, dos interessados.

Apel se contrapõe a esta perspectiva e suas implicações, pois, para ele, o meramente privado é irracional e mais, "nem mesmo a autonomia de uma decisão chamada livre é possivel ser garantida, quando ela só pode ser fundamentada privadamente por si própria [...]" (p. 178), pois “[...] a identificação de uma decisão privada com uma decisão existencialmente livre [...] se baseia em uma ilusão" ( $p$. 179), ilusão esta que é patrocinada pela ideologia do sistema de complementaridade ocidental (filosofia analítica-existencialismo).

Neste horizonte, enquanto a liberdade se apresenta como decisão arbitrária e meramente privada, no sentido de uma privacidade irracional, ela é, embora concebida como existente, incapaz de responsabilidade ética. Para Apel, no entanto, não se pode excluir a liberdade e a responsabilidade subjetiva em favor da objetividade científica, isenta de valoração, pois ao tentarmos fazer isto se manifesta o incontestável conteúdo de verdade do sistema de complementaridade ocidental, ou seja, "[...] ciência objetiva e liberdade e responsabilidade subjetivas dos sujeitos da ciência se pressupõem reciprocamente. Um se afirma e cai no outro" (p. 181).

\section{As condições metodológicas de possibilidade de legitimação da norma ética fundamental}

De acordo com o exposto nos pontos anteriores, um dos desafios que enfrenta a Humanidade hoje é responder, com responsabilidade, aos efeitos principais e colaterais de suas ações em medida planetária, de modo que indagar sobre a possibilidade de fundamentar filosoficamente uma orientação ético-política para nossa era significa indagar sobre a possibilidade e necessidade de uma macroética, ou seja, uma ética não circunscrita à responsabilidade moral de cada um diante do próximo e nem tão pouco circunscrita à responsabilidade política no sentido da "razão de estado".

Neste horizonte, cabe à "razão prática" dar uma resposta para a situação que ela mesma criou com base na "razão técnica" e assim responder se cabe ao ser humano como ser liberado da natureza, ou seja, como ser que se destacou dos domínios deterministas das leis da natureza ser direcionado para princípios normativos de uma ética.

Nesta direção dirige-se o pensamento de Apel, como demonstra a seguinte afirmação: "Meu questionamento filosófico em face da atual crise do sistema planetário da humanidade é, por conseguinte, a questão sobre a possibilidade de uma orientação ético-política fundamental' (p. 164). 
Entretanto, parece que a fundamentação de uma ética intersubjetivamente válida nunca foi tão difícil quanto hoje em dia, pois "[...) a ciência modera (science) pré-ocupa o conceito de fundamentação racional, intersubjetivamente válida, no sentido da neutralidade valorativa" (p. 165), de modo que a partir deste parâmetro todas as formações teóricas não isentas de valoração parecem ser meras ideologias; assim, por conseguinte, parece ser impossível uma ética racional da superação de conflitos, pois tal ética aparece como simples ideologia.

Ora, Apel não pretende, a partir da situação atual do ser humano, deduzir algo como a necessidade de uma responsabilidade ética, pois isto implicaria uma falácia naturalista, ou seja, na dedução de um dever a partir de um ser. No entanto, o fato de cada argumentante ter reconhecido, implicitamente, a norma básica faz parte da situação humana, ou seja, é um fato e mais, "[...] este factum singular pode ser decifrado no sentido de um perfectum a priori, como o necessário reconhecimento das condições normativas da argumentação" (p. 201).

Pois bem, poderiamos pensar que a postulação anterior conduz a uma falácia naturalista pois foram extraídas conseqüências normativas do fato da argumentação; entretanto, para Apel, isto não acontece, pois não se deduz estas conseqüências de um factum antropológico contigente e sim da circunstância de que é indiscutivelmente verdade que, cada um, como argumentante, já reconheceu condições normativas de possibilidade da argumentação; condições estas que, por serem condições de possibilidade, são transcendentais, logo, não deduzíveis de fatos, ou seja, condição de possibilidade dos próprios fatos..

Assim sendo, para Apel "[...] cada um que filosofa - pelo menos implicitamente - também já deve ter reconhecido uma norma ética fundamental" (p. 198), ou seja, deve reconhecer que ele como argumentante, simultaneamente com a possibilidade do sentido e da verdade, também já pressupõe que as pretensões humanas de sentido e da verdade devem, em princípio, ser resgatáveis por argumentos e apenas por argumentos.

Deste modo, quem argumenta já reconhece que ele como argumentante pressupõe na qualidade de parceiro de iguais direitos uma comunidade de comunicação, na qual todas as diferenças de opinião - também aquelas que dizem respeito às normas éticas - só podem ser resolvidas por argumentos geradores de consenso; de onde se conclui, que "a norma ética fundamental, que qualquer argumentante [...] reconheceu necessariamente, consiste, por conseguinte, no estar obrigado à metanorma da argumentativa formação do consenso sobre normas situacionalmente relacionais"' (p. 199).

Pois bem, com isso se reconheceu que o discurso argumentativo de todos os possíveis atingidos é a instância ideal de fundamentação e legitimação de todas as normas problematizáveis, o que implica uma assimetria na relação do discurso argumentativo com todas as demais formas de comunicação e vida; de onde se pode concluir que "somente no âmbito e com base nas regras do jogo do discurso podem ser fundamentados juízos válidos, teorias, normas, etc., sobre as formas não discursivas [...]" (p. 199). 


\section{O problema da racionalidade ética e a fundamentação de uma orientação ético-política}

Segundo Apel, pensa-se hoje em dia sob o conceito de racionalidade não uma pluralidade de racionalidades, mas uma racionalidade univoca que pode ser contraposta ao irracional ou ao arracional. O conceito de racionalidade é por vezes entendido no sentido de uma conclusão lógica e, respectivamente, de um cálculo matemático valorativamente neutro e instrumentalizado para os mais diversos fins que são postos como base da razão teórica e prática.

Esta concepção de racionalidade conduz ao que Apel denomina sistema de complementaridade da ideologia ocidental. De acordo com este sistema, ocorre, no âmbito da ciência, uma racionalidade instrumental valorativamente neutra que se complementa, no campo prático, por uma escolha irracional dos axiomas últimos da valoração. Ora, isto significa que "[...] deve a práxis no âmbito da vida pública [...], da política, do direito e da ciência, etc., ser regulada exclusivamente pela racionalidade não valorativa da ciência e da técnica" (p. 109 e 210) e, em face disso, a moral é um assunto de vida privada.

Apel discorda do conceito de racionalidade valorativamente neutra e entre outras razões, porque "[...] uma organização da responsabilidade moral para as consequiências das ações coletivas dos homens [...] não será possível sob os pressupostos do sistema de complementaridade" (p. 210). Pois bem, segundo os pressupostos deste sistema há uma distinção entre legalidade e moralidade, logo, entre a instituição de normas e o discurso ético-filosófico. Nesta perspectiva, é, em princípio, negado ao discurso ético-filosófico a possibilidade de resultados intersubjetivamente válidos, portanto, a sua possibilidade de legitimação e crítica do processo de constituição e cumprimento de normas institucionalizáveis.

Pode-se dizer, então, que "[...] em decorrência do sistema de complementaridade, não existe nenhum problema de legitimação racional, além da conđuta institucionalizável" (p. 211), de modo que são postos como fundamentos da democracia os acordos, no sentido da decisão democrática de normas.

Assim sendo, uma ética da responsabilidade pública é encarada como utópica e só é considerada fundável uma possível racionalidade para a submissão de cada um às regras, no âmbito do sistema de regras convencionais estabelecido; ou seja, "não é considerada como possivel a fundamentabilidade racional e a regulabilidade de uma responsabilidade, no sentido da participação de cada um em processos públicos de organização de uma responsabilidade solidária de instituições [...]" (p. 212).

Pois bem, nesta ótica, o único fundamento de normas publicamente válidas parece consistir nas decisões da vontade subjetiva de cada um e que se formam no âmbito privado, aquém de todas as normas intersubjetivamente válidas, pois um acordo democraticamente regulado parece um compromisso estratégico entre as relações, não fundáveis, de vontade dos indivíduos e de seus representantes.

Para Apel, os defensores deste acordo, na falta de um conceito de racionalidade comunicativo consensulal, não são capazes de reconhecer a necessária conexão entre a moral da consciência privada e uma racionalidade valorativa que fun- 
damenta o agir coletivo e mais, segundo ele, o erro que está na base desta concepção de acordo transparece no seguinte fato: "[...] na circunstância de existirem condições normativas de possibilidade de acordos que não podem mais ser, elas próprias, fundadas em acordos [...]; assim, por exemplo, a norma ética e jurídica de cumprir acordos" (p. 213).

Ora, para Apel, esta norma concorda abertamente com a norma mais ainda fundamental de aspirar a acordos no caso de conflitos práticos, fundada sobre a norma básica de uma ética de comunicação consensual. Pois bem, isto implica a intermediação racional entre a moral da consciência do indivíduo e uma moral publicamente válida, pois "[...] sem a pressuposição subjetiva da capacidade de consenso numa comunidade ideal de comunicação, também a consciência do indivíduo, no sentido da ética da comunicação, não pode ser congente com ele próprio" (p. 213).

Do exposto até aqui, podemos distinguir duas formas de racionalidade prática: a racionalidade prática comunicativo-consensual e a racionalidade prática de ação estratégica. Ambas as formas de racionalidade são formas de comunicação e interação entre os homens enquanto sujeitos da ação, porem, para Apel

"[...] apenas a racionalidade comunicativo-consensual pressupōe regras ou normas que se encontram, a priori, além do interesse pessoal bem calculado de cada um; a racionalidade estratégica, ao contrário, se fundamenta exclusivamente na reciprocidade de adoção técnico-instrumental da racionalidade da ação prática, na convivência entre os homens. E, [...] ela [...] não pode ser nenhuma base contrafática para ética" (p. 214).

Para Apel, não é fácil sustentar a diferença entre a racionalidade ética de comunicação consensual e a racionalidade estratégico-instrumental. Pois bem, é ambíguo, por exemplo, quando entendemos a norma ética como diretriz para aspirar acordos em caso de conflito, pois mesmo o acordo pode ser entendido como um problema de cooperação, estratégia.

Ora, se a base dos acordos livres, que fundamenta o direito, for buscada exclusivamente na liberdade arbitrária e no interesse pessoal, estrategicamente calculado de cada um, então, para Apel, não se poderia entender por que cada um deveria seguir um contrato sem reserva criminal, já que, neste caso, o contrato depende da circunstancialidade arbitrária dos interesses.

Apesar de suas diferenças, há, para Apel, uma relação clara entre racionalidade consensual e racionalidade estratégica e esta diferença implica um dever ser para a razão prática. Ora, Apel não põe em dúvidas que a interação humana real e até a comunicação pela linguagem também têm e sempre devem ter traços estratégicos, no entanto, para ele, já na interação humana estratégica devemos supor, desde logo, um principio de transubjetividade ética da comunidade comunicativo-consensual, pois

“[...] não é possível que, na comunidade de argumentação de um discurso [...] possamos estar de comum acordo, $[\ldots]$ baseados numa interação estratégica, sobre o conceito de racionalidade estratégica ou sobre a verdade ou falsidade da tese, segundo a qual, toda interação é estratégica" (p. 220). 
Pois bem, isto não é possivel porque “[...]todas as comunicações humanas [...] já devem sempre ter tido parte no princípio da transubjetividade não estratégica" (p. 221) para ser possível. É a partir deste horizonte que, para Apel, pode ser proposta a seguinte concepção fundamental de uma ética política:

“[...] o pensamento estratégico, que se relaciona com a auto-afirmação dos diversos sistemas políticos - e em última instância dos indivíduos - em cada caso, na situação concreta, deveria ser intermediado por uma estratégia finalistica de longo prazo na moral consensual" (p. 220).

Ora, esta estratégia finalística da moral consensual brota da norma básica da moral consensual e da condição contraposta (contigente) da situação humana que é vivida em um mundo, no qual não podemos contar, sem mais e nem menos, que a norma básica da moral consensual seja obedecida.

Podemos concluir, então, que a estratégia finalista que se impõe implica que nós deveríamos tentar sempre contribuir para a realização de relações políticas exigidas pela norma ética básica e antecipadas contrafaticamente no discurso argumentativo.

\section{A fundamentação racional da ética e a possibilidade de uma orientação ético-política fundamental}

A proposta de Apel é “[...] esboçar um ponto de partida filosófico de uma ética que [...] é capaz de desfazer a aparência da impossibilidade de uma fundamentação racional de normas intersubjetivamente válidas e que poderia fornecer um parâmetro crítico para a desejada reorientação política" (p. 185) e para isto ele propõe como necessário o questionar, ao menos em parte, as três premissas axiomáticas pressupostas na filosofia analítica e que "impedem" uma fundamentação última.

É neste horizonte que Apel se propõe a questionar a equiparação da fundamentação filosófica com a dedução lógica de sentenças a partir de sentenças e a equiparação de validade intersubjetiva com a validade objetiva de conclusões isentas de valor ou de constatações de fato.

Assim sendo, ele pretende demonstrar, em primeiro lugar, que “[...] a fundamentação última de natureza filosófica não pode ser equiparada com a dedução lógico-formal, mas antes com a reflexão sobre as condições subjetivointersubjetivas de possibilidade de argumentação intersubjetivamente válida" ( $p$. $185)^{2}$ e, em segundo lugar, que "[...] às condições subjetivo-intersubjetivas de possibilidade de toda argumentação, pertencem normas básicas de uma ética intersubjetivamente válida" (p. 185).

2 Para Apel, "[...] a abstração da dimensão pragmática da argumentação, caracteristica da filosofia analítica, devia para a tendência de se pensar o problema da "fundamentação última", unicamente como um problema de pressupostos lógicos (sintático-semânticos) de sentenças e, respectivamente, de proposições" (APEL, Karl-Otto. Transformación de la filosoffa. Madri: Taurus, 1985, p. 364). Ora, a abstração da dimensão pragmática da linguagem e da argumentação implica, conforme Apel, a impossibilidade de uma reflexão sobre as condiçōes, por nós sempre pressupostas, de possibilidade da argumentação, de modo que com esta abstração não se pode perceber nenhuma dimensão última legitimamente fundada, pois essa aparece como uma quebra arbitrária da argumentação ou um recurso a um dogma. (A este respeito verificar Apel, op. cit., p. 364 e 365; e Le logos propre au langage humain, Edition de L'Éclat, 1984, p. 38 a 53.) 
Pois bem, para Apel, se for possível demonstrar que a argumentação lógica, como condição de possibilidade, já pressupõe uma ética intersubjetivamente válida, então se estaria em condições de adotar um principio da ética, indiscutível para todos os que se puserem em argumentação, o que implicaria um abrir mão do bloqueio cientificista da racionalidade ética.

Ora, segundo Apel, as condições de possibilidade de uma argumentação racional não só pertencem à competência lingüística que cada um traz consigo, mas pressupõem uma comunidade ideal de comunicação, em princípio ilimitada, na qual uma compreensão de sentido e uma formação de consenso sobre pretensões práticas devem ser, em princípio, possivel; por conseguinte, "com a suposição, a priori necessária, de uma comunidade ideal de comunicação [...] também a validade intersubjetiva de uma ética normativa da comunidade ideal de comunicação já deve ser sempre suporte e subjacente" (p. 187).

Pois bem, isto significa dizer que ninguém pode, nem mesmo consigo, entender-se corretamente se, em princípio, já não reconhecer todas as normas de uma correta comunicação, nas condições de um reconhecimento recíproco dos parceiros da comunicação, e sem esta suposição, expressa ou inexpressa, sem dúvida qualquer discurso levado a sério deixaria de ter sentido.

Com isso, então, se demonstra que não se sustenta o conceito de racionalidade intersubjetiva do cientificismo, que reduziu a racionalidade à objetividade, no sentido da validade de asserções isentas de valoração; ora, para Apel, “[...] a objetividade da ciência, isenta de valoração, ainda pressupõe, ela mesma, a validade intersubjetiva de normas éticas" (p. 188).

Poderiamos pensar que pouco se conquistou para a ética com o a priori da comunidade de argumentação, pois ele apenas implica a pressuposição de uma ética argumentativa correta abstraída das necessidades concretas dos argumentantes. Entretanto, para Apel, pensar isso seria falacioso, pois, deste modo, se desconsidera que "[...] o domínio dos possiveis contextos de argumentação [...] não pode ser delimitado (reduzido) pelo princípio da argumentação [...]” (p. 188). Ora, para Apel, junto com pretensões defensáveis pela argumentação, podem ser afirmados argumentativamente todos os interesses e necessidades individuais e particulares conciliáveis com os de todos os outros.

Deste modo, "resulta [...] como implicação de uma ética da comunidade ideal de argumentação, a exigência de uma intermediação conteudística de todos os interesses humanos [...]" (p. 188) e, assim, a ética do discurso prático exige que seja constituída a situação da deliberação livre de repressão, ou seja, a situação de liberdade política, situação na qual possa ser conseguido o consenso acima de todas as pretensões conteudísticas particulares de todos os membros da comunidade de comunicação, o que implica a criação de uma instituição de deliberação universal.

Esta instituição de deliberação universal está, para Apel, implícita no a priori da comunicação e deve ser vista não só como metainstituição de todas as instituições sociais contingentes surgidas na história, mas como a instância de legitimação e de deslegitimação de todas as instituições de fato existentes ou a serem criadas. 
Para Apel, o pressuposto da comunidade de comunicação, implicado em todo discurso, estabelece o parâmetro ético que, ao se confrontar com a realidade, as dificuldades e os limites reais de uma práxis ético-politica, implica o destacar e conquistar bases para estratégias de longo prazo, o que pode ser mostrado em dois postulados éticos políticos que podem ser deduzidos da contradição entre o ideal de uma ética de comunicação e a realidade sociopolítica.

O primeiro postulado ético-político resulta da contradição entre a comunidade ideal e a real de comunicação, necessariamente antecipada de forma contrafática. Pois bem, para Apel, cada um que argumenta pressupõe necessariamente uma situação ideal de fala e uma comunidade ideal de comunicação, porém, sabe que ele mesmo e seus parceiros não satisfazem ao pressuposto necessário, de onde resulta o primeiro postulado, ou seja: esta contradição entre comunidade ideal e real de comunicação deve ser superada historicamente.

O segundo postulado ético-político resulta da percepção de que a comunidade ideal de comunicação deve ser realizada na comunidade real de comunicação. Ora, isto implica no postulado ético-político segundo o qual "[...] deve ser assegurada para a comunidade real de comunicação a conservação de sua existência" (p. 190; grifo nosso), pois ela é pressuposto necessário para a realização da comunidade ideal de comunicação.

Neste horizonte, para Apel, "a exigência da responsabilidade solidária dos seres humanos deve ser cumprida, embora as condições de possibilidade de seu cumprimento nem sequer tenham sido constituídas" (p. 191). Esta exigência resulta em uma orientação ético-política fundada no pressuposto ineliminável de uma comunidade ideal de comunicação e seu princípio ético, implicado em todo o falar e agir humano, estabelece a orientação para o agir político.

Deste modo, o político que atua sob uma tal orientação ética de base deve esforçar-se com recursos políticos, no sentido de uma estratégia de longo prazo, para atuar sob a intermediação dos imperativos emancipatórios e isto implica que para ele são já obrigatórias aquelas normas éticas de comunicação e deliberação, cujas condições reais ele se esforça por realizar.

Assim, portanto, para Apel, devem os políticos e não só eles, mas todos os indivíduos humanos, enquanto argumentantes, não só pressupor a possibilidade de uma comunidade ideal de comunicação no sentido da norma ética básica, mas até antecipar contrafaticamente sua existência enquanto argumentam.

Ora, a necessidade de antecipação contrafática das condições ideais da formação do consenso é importante pela seguinte razão: por esta antecipação é apresentado um telos normativamente fundamentado que não é idêntico com 0 atual estado da sociedade dos construtores, mas antes com o estado a ser ambicionado por qualquer possível comunidade de argumentantes.

Pois bem, para Apel, esta antecipação contrafática da comunidade ideal de comunicação aponta para o futuro no sentido de uma idéia reguladora do progresso moral, que pode ser reconhecida por qualquer um que argumente, e que é condição de possibilidade do entendimento e tolerância da unidade e multiplicidade das culturas humanas. 
Podemos postular, portanto, com Apel, que a reconstrução da situação histórica deve ser sempre tentada, pois, a partir da racionalidade crítica do discurso consensual temos o parâmetro para a atuação teórico-prática, logo, também éticopolítica, do processo da realização humana.

\section{Conclusão}

Para Apel, a comunidade humana passa atualmente por uma situação que envolve vários riscos, riscos estes que colocam em ameaça a própria existência humana. Pois bem, para ele, só agora se tornou plenamente eficaz a intervenção da ciência e da técnica nos domínios da Natureza e da vida, o que acarretou sérias conseqüências como a ameaça da guerra nuclear de extermínio, a escassez de reservas energéticas, a destruição ambiental, etc.

É, portanto, um desafio da comunidade humana atual enfrentar com responsabilidade os efeitos colaterais de suas ações em medida planetária, pois suas conseqüências têm alcance planetário e envolvem riscos que exigem respostas urgentes e eficazes, sob pena de aniquilamento da própria espécie humana.

Para Apel, então, cabe à razão prática dar uma resposta à situação que ela mesma criou com base na razão técnica, ou seja, cabe a razão prática indagar sobre a possibilidade de uma orientação normativa para as ações humanas, logo, uma orientação ético-política, que seja capaz de responder aos desafios do atual sistema planetário da Humanidade.

Entretanto, paradoxalmente, a ciência que por suas seqüelas tecnológicas se constitui em causa para a necessidade do enfrentamento das conseqüências das ações humanas orientadas cientifica e tecnologicamente e que constituíram esta ameaça à vida humana, ela mesma, através do conceito de racionalidade por ela elaborado, aponta para a impossibilidade de uma tal orientação ética.

Apel se propõe, portanto, a questionar o conceito de racionalidade científica que compreende a atividade científica e racional como atividades isentas de valoração e que, por conseqüência, apontam para a impossibilidade de fundamentação de uma orientação ético-política, a qual é indispensável para o enfrentamento da atual crise da Humanidade.

Nesta perspectiva, ele questiona a equiparação da fundamentação filosófica com a dedução lógico-formal de sentenças, a partir de sentenças, e também a equiparação de validade intersubjetiva com a validade objetiva de conclusões isentas de valoração; ora, a fundamentação filosófica não pode ser equiparada à dedução lógico-formal, mas à reflexão transcendental sobre os pressupostos inelimináveis da argumentação intersubjetiva, que é a única capaz de fundamentar racionalmente o saber e agir humanos.

Neste horizonte, para Apel todo e qualquer falante, sob pena de cair em autocontradição performativa, pressupõe já os pressupostos inelimináveis do discurso e portanto, também, uma ética intersubjetivamente válida. Ora, se o discurso pressupõe necessariamente uma ética intersubjetivamente válida e que é condição de possibilidade de todo e qualquer ato de fala com sentido, então, até mesmo quem nega o princípio ético o pressupõe como condição de possibilidade de sua negação e, portanto, o afirma. 
Assim, então, a razão comunicativa contém implícita em si o princípio ético capaz de orientar normativamente todo o pensar e agir humanos e, para Apel, este princípio, que é capaz de fornecer uma orientação ético-política às ações humanas, é indiscutivel e aceitável para todos os que se ponham na argumentação e inclusive para os que argumentativamente o negam, pois, a negação o pressupõe.

Ora, a irrecusabilidade do princípio ético implícito em todo o discurso humano implica a insustentabilidade racional do bloqueio cientificista da racionalidade ética, pois a própria objetividade científica da ciência isenta de valor pressupõe a norma ética fundamental. Podemos concluir, então, com Apel, que a razão humana teórica e prática é capaz de legitimar-se e só precisa do compromisso humano para realizar-se no mundo.

\section{Referências bibliográficas}

ALBERT, Hans. Tratado de razão crítica. Rio de Janeiro, 1976.

APEL, Karl-Otto. Diskurs und Verantwortung. Frankfurt, 1988.

- Estudios éticos. Barcelona, 1986.

- Ethique de la discussion. Paris, 1994.

- La transformatión de la filosofia. Madri, 1975. t. I e II.

—. Semiótica filosofica. Buenos Aires, 1994.

—. Teoria de la Verdad y Ética del Discurso. Barcelona, 1991.

- Understandig and Explanation. Cambridge, Massachusetts e Londres, 1984. CORTINA, Adela. Razón comunicativa y responsabilidad solidaria. Salamanca, 1995. 